\title{
A exigência conceitual na prática pedagógica de dois professores de Química que ensinam Química e Física
}

\author{
The conceptual demand in the pedagogical practice \\ of two chemistry teachers who teach Chemistry and Physics
}

\author{
Rosilene Ventura de Souza ${ }^{1}$. https://orcid.org/0000-0003-1763-0984 \\ Bruno Ferreira dos Santos ${ }^{2}$. https://orcid.org/0000-0002-9522-2268
}

\begin{abstract}
Resumo: Este artigo apresenta uma pesquisa sobre os níveis de exigência conceitual da prática pedagógica de dois professores que lecionam Química e Física no Ensino Médio regular. Esses professores são formados em Química, mas também ensinam Física, uma prática comum nas escolas públicas brasileiras, relacionada com o déficit de professores de Ciências. A pesquisa foi realizada em duas escolas urbanas e envolveu a observação participante em sala de aula. Para a coleta de dados, utilizamos gravadores de áudio, diário de campo e entrevistas semiestruturadas. Nossa pesquisa está subordinada à teoria do discurso pedagógico de Basil Bernstein e à noção de exigência conceitual proposta por Ana Maria Morais e seus colaboradores. Nossos resultados apontam que as práticas pedagógicas de tais professores apresentam uma baixa exigência conceitual nas duas disciplinas que lecionam, sendo a formação inicial e o nível socioeconômico dos estudantes fatores que contribuem para essa característica.
\end{abstract}

Palavras-chave: Prática pedagógica. Conceitos. Ensino médio. Ensino de química. Ensino de física.

\begin{abstract}
This article presents research on the levels of conceptual demand of the pedagogical practice of two teachers who teach Chemistry and Physics in secondary schools. These teachers were trained in Chemistry, but also teach Physics, a common practice in Brazilian public schools related to the shortage of Science teachers. Our research is based on Basil Bernstein's theory of pedagogical discourse and on the notion of conceptual demand proposed by Ana Maria Morais and collaborators. The research was carried out in two urban schools in Jequié, Bahia, Brazil, and involved participant observation in the classroom. For the data collection we used audio recorders, field notebooks and semi-structured interviews. Our results point out that the pedagogical practices of these teachers show a low conceptual demand in the two subjects they teach, being influenced by their teacher training and the social economic background of the students are factors that contribute to this feature.
\end{abstract}

Keywords: Pedagogic practice. Concepts. Secondary education. Chemistry teaching. Physics teaching.

\footnotetext{
${ }^{1}$ Universidade Estadual do Sudoeste da Bahia (UESB), Departamento de Ciências Exatas e Naturais, Itapetinga, BA, Brasil. E-mail: <rosilene.vsouza@yahoo.com.br>.

${ }^{2}$ UESB, Departamento de Ciências e Tecnologias, Jequié, BA, Brasil.
} 


\section{Introdução}

Neste trabalho apresentamos e discutimos os resultados de uma pesquisa acerca das interações discursivas em sala de aula como subsídio para o estudo da prática pedagógica de professores licenciados em Química que também lecionam Física, em escolas públicas de Ensino Médio. A situação de professores que lecionam disciplinas diferentes da sua formação é uma prática comum nas escolas brasileiras, e ocorre principalmente devido ao déficit de professores com formação específica nas áreas de conhecimento.

Pesquisas como o relatório de auditoria coordenada abordando o Ensino Médio do Tribunal de Contas da União (BRASIL, 2014), o documento que trata sobre o perfil da docência no Ensino Médio regular (INEP, 2015), as notas estatísticas do Censo Escolar 2017 (INEP, 2018a) e o relatório do segundo ciclo de monitoramento das metas do plano nacional de educação 2018 (INEP, 2018b), por exemplo, denunciam a área das Ciências como a mais preocupante em relação ao déficit de professores, sendo os casos mais graves encontrados nas disciplinas de Física e Química, e em maior número nos Estados da Bahia, Mato Grosso, Tocantins e Goiás.

O documento que trata sobre o perfil da docência no Ensino Médio regular, elaborado com base nos dados do censo escolar 2013 (INEP, 2015) procurou avaliar a formação inicial dos docentes que atuam no Brasil, por disciplina, e o esforço que esses profissionais empreendem para o exercício de suas funções. O cenário desejado é que o professor tenha a devida qualificação acadêmica para ministrar a disciplina que lhe é atribuída, que atue em uma única escola e que destine até dois terços de sua jornada de trabalho à sala de aula. No entanto, entre outras características do perfil do professor de Química, esse documento aponta que, além da disciplina de Química, 52,9\% dos professores também lecionam Física.

Resultados de pesquisas abordando o problema de déficit de professores apontam que a carência de professores de Ciências na Educação Básica parece não estar na oferta desses cursos de nível superior e sim na desvalorização da carreira docente, o que tem afastado tanto os graduandos, no decorrer do curso de licenciatura, quanto os profissionais já formados, que buscam atuar em outras áreas que apresentam maior "prestígio social", como a pesquisa e a docência no Ensino Superior.

Mas aqui o nosso foco se situa nos licenciados em Química que estão em exercício docente na Educação Básica. Profissionais que muitas vezes ainda têm de enfrentar a situação de assumirem disciplinas que não são aquelas de sua formação. E é aí que podemos perceber a dimensão do problema do déficit de professores de Ciências no Brasil, pois os professores licenciados que atuam em sala de aula estão longe de atender à demanda do ensino escolar, podendo afetar o ensino e aprendizagem dos alunos e também o seu desenvolvimento profissional.

Buscamos uma melhor compreensão do cenário em que professores de Química estão atuando no Ensino Médio na dualidade especialista/leigo, por acreditarmos que essa situação de algum modo afeta o processo de ensino e aprendizagem das Ciências, podendo comprometer o desenvolvimento de uma sólida educação científica dos estudantes. Desse modo, nosso principal objetivo foi analisar e contrastar o nível de exigência conceitual da prática pedagógica de professores formados em Química que atuam na docência nas disciplinas de Química e Física no Ensino Médio regular, e tivemos a Teoria do Discurso Pedagógico de Basil Bernstein como principal aporte teórico de nosso estudo. 


\section{O código pedagógico}

Basil Bernstein, ao buscar estabelecer uma descrição que permitisse a integração entre os níveis macro e micro social nos processos educacionais, desenvolveu uma teoria que nos permite compreender como as relações de classe geram desigualdades sociais, sendo essas desigualdades realizadas na criação, organização, distribuição e reprodução dos valores materiais e simbólicos da sociedade. Para compreender esses processos, Bernstein utiliza as noções de poder e controle.

Para esse sociólogo, o modo como a sociedade seleciona, classifica, distribui, transmite e avalia o conhecimento educacional formal reflete na distribuição de poder e nos princípios de controle social. Bernstein desenvolveu os conceitos de classificação e enquadramento associados ao poder e ao controle, que podem ser usados na investigação da sala de aula (DOMINGOS et al., 1986). Enquanto a classificação traduz as relações de poder, possibilitando do exame das relações que ocorrem entre as categorias (agentes, discursos, práticas), o enquadramento traduz as relações de controle sobre a comunicação (pais e filhos, alunos e professores), viabilizando o exame das relações que ocorrem dentro das categorias (BERNSTEIN, 1998).

\section{A exigência conceitual}

A exigência conceitual é um conceito proposto por Ana Maria Morais, com base em pesquisas empíricas desenvolvidas sob a perspectiva da teoria sociológica de Basil Bernstein. De acordo com a autora, a capacidade cognitiva dos alunos pode ser mobilizada pela escola por meio de um elevado nível de abstração do conhecimento (como a utilização de conhecimentos adquiridos em novas situações), no qual os alunos podem desenvolver a capacidade de justificar, relacionar e interpretar; ou por meio de um baixo nível de abstração do conhecimento (quando apenas adquirem conhecimento), que desenvolve apenas a memorização, exemplificação e descrição (MORAIS, 1991).

O conceito de exigência conceitual da prática pedagógica de professores de Ciências inclui dimensões como a complexidade das capacidades cognitivas, que trata dos processos mentais que estão envolvidos no processo de ensino-aprendizagem, e as dimensões que analisamos em nosso estudo: (1) a complexidade dos conhecimentos científicos na abordagem de conteúdos; (2) a intradisciplinaridade - relação entre os conteúdos de uma mesma área especifica da Ciência e a interdisciplinaridade - relação entre conteúdos de diferentes áreas da Ciência; (3) discurso acadêmico ou discurso científico e discurso não acadêmico ou discurso de senso comum (CALADO; NEVES; MORAIS, 2013). De acordo com Morais (1991), a Ciência é marcada por níveis elevados de abstração, sendo necessário que, para o sucesso escolar nessa área do conhecimento, a exigência conceitual da prática pedagógica seja também elevada.

\section{Metodologia da pesquisa}

Para alcançarmos o objetivo da nossa pesquisa adotamos uma metodologia de investigação qualitativa. A pesquisa foi desenvolvida no município de Jequié, BA. Para seleção da escola e dos professores participantes do nosso estudo, utilizamos os dados do Instituto Nacional de 
Estudos e Pesquisas Educacionais Anísio Teixeira (INEP) relativos às notas do Exame Nacional do Ensino Médio (ENEM) em sua edição do ano de 2014, por escola (MORENO; TENENTE; LUIZ, 2015). Ao selecionarmos apenas as escolas estaduais do município de Jequié, obtivemos como resultado o Quadro 1.

Com essa relação definimos três critérios para a escolha: escolas com professores licenciados em Química que lecionassem as disciplinas de Química e Física; escolas cujos estudantes pertencessem a diferentes níveis socioeconômicos; escolas com diferentes médias de resultado para o ENEM 2014. Assim, duas escolas atenderam aos nossos critérios, que chamaremos de Escola A, sendo o professor dessa escola participante de nosso estudo identificado como P1; e de Escola B, com o professor P2, participante de nosso estudo.

Por meio da observação participante realizamos a nossa coleta de dados. Os instrumentos utilizados foram o diário de campo, gravadores de áudio e entrevistas semiestruturadas. As observações ocorreram entre os dias 3 de agosto e 13 de novembro de 2015. Ao final, foram observadas 58 aulas de 50 minutos de duração cada, que geraram 48 horas e 33 minutos de áudio. As entrevistas produziram 1 hora e 43 minutos de áudio. O diário de campo foi finalizado com um total de 45 páginas de anotações das observações.

Quadro 1. Notas do ENEM 2014 por escola

\begin{tabular}{|l|l|l|l|l|l|c|}
\hline $\begin{array}{c}\text { Nome da } \\
\text { escola }\end{array}$ & Município & UF & Rede & $\begin{array}{c}\text { Indicador de } \\
\text { permanência } \\
\text { na escola }\end{array}$ & $\begin{array}{c}\text { Indicador } \\
\text { de nível } \\
\text { socioeconômico }\end{array}$ & $\begin{array}{c}\text { Média da } \\
\text { escola (provas } \\
\text { objetivas) }\end{array}$ \\
\hline EE - Escola C & Jequié & BA & Estadual & de $60 \%$ a $80 \%$ & Médio & 538,21 \\
\hline EE - Escola B & Jequié & BA & Estadual & de $60 \%$ a $80 \%$ & Médio & 508,49 \\
\hline EE - Escola D & Jequié & BA & Estadual & $80 \%$ ou mais & Médio baixo & 482,97 \\
\hline EE - Escola A & Jequié & BA & Estadual & de $60 \%$ a $80 \%$ & Médio baixo & 474,45 \\
\hline
\end{tabular}

Fonte: Moreno, Tenente e Luiz (2015).

Todos os áudios das aulas e das entrevistas foram transcritos. Analisamos cada aula com o intuito de fragmentarmos as transcrições em episódios. Os episódios selecionados correspondem às dimensões da exigência conceitual investigadas, podendo um mesmo episódio estar agrupado em mais de uma dimensão. Assim, usamos indicadores que são instrumentos de análise desenvolvidos pelo grupo Estudo Sociológico em Sala de Aula (ESSA) ${ }^{3}$, mas também desenvolvemos novos indicadores adaptados às nossas questões de pesquisa. Ao analisarmos o nível de exigência conceitual da prática pedagógica dos professores nas disciplinas de Química e

\footnotetext{
${ }^{3}$ Grupo de investigação integrado no Instituto de Educação e Centro de Investigação em Educação da Universidade de Lisboa que pretende valorizar a perspectiva sociológica na análise educacional. Mais informação em: <http://essa.ie.ulisboa.pt/indexport.htm>.
} 
Física investigamos as seguintes dimensões: relações intradisciplinares, relações interdisciplinares, relação entre conhecimentos acadêmicos e não acadêmicos, e complexidade dos conhecimentos científicos. Dessa forma, buscamos identificar e analisar os conhecimentos científicos e em que nível estão sendo empregados na prática pedagógica de cada professor. Os indicadores de análise utilizados apresentam valores de classificação que variam entre muito forte $\left(\mathrm{C}^{++}\right)$, forte $\left(\mathrm{C}^{+}\right)$, fraco $\left(\mathrm{C}^{-}\right)$e muito fraco $\left(\mathrm{C}^{-}\right)$e graus de complexidade para os conhecimentos científicos.

\section{Resultados e discussão}

\section{Relações Intradisciplinares e Interdisciplinares}

As relações intradisciplinares são definidas como aquelas que relacionam os distintos conhecimentos científicos que estão presentes numa mesma área do saber ou disciplina (MORAIS; NEVES, 2012). No que se refere às relações interdisciplinares, essas são estabelecidas de acordo com uma temática desenvolvida na disciplina, um objeto de conhecimento ou uma abordagem em que duas ou mais disciplinas intencionalmente estabelecem relações entre si para alcançar um conhecimento mais abrangente e, ao mesmo tempo, diversificado e unificado (COIMBRA, 2000). Tanto nas relações intradisciplinares quanto nas interdisciplinares os valores muito fortes de classificação $\left(\mathrm{C}^{++}\right)$vão corresponder à ausência de relações entre os conhecimentos; um valor muito fraco de classificação $\left(\mathrm{C}^{-}\right)$corresponde ao estabelecimento de relações entre conhecimentos; e os valores intermediários de classificação $\left(\mathrm{C}^{+}\right.$e $\left.\mathrm{C}^{-}\right)$correspondem a relações intermediárias entre conhecimentos (MORAIS; NEVES, 2012).

Para analisar a prática pedagógica dos professores P1 e P2 nas disciplinas de Química e Física, construímos dois indicadores para cada dimensão da exigência conceitual (intradisciplinaridade e interdisciplinaridade), conforme apresentamos nos quadros 2 e 3. Por meio deles buscamos analisar o quanto os professores realizam a articulação entre os conhecimentos durante as aulas e nas atividades e tarefas que solicitam aos alunos.

Nossas análises indicaram que, na disciplina de Química, o professor P1 não busca promover a relação entre os conteúdos já estudados e os novos conteúdos que estão sob estudo. Já na disciplina de Física, o professor P1 retoma conceitos e conteúdos estudados anteriormente com muito mais frequência para explicar os novos conceitos. Esse resultado aponta que, embora o professor P1 na disciplina de Física apresente uma tendência em retomar conceitos já estudados na explicação de conceitos novos, ele apresenta mais dificuldades em avançar nos conteúdos dessa disciplina. No caso do professor P2, as relações intradisciplinares são mais favorecidas em sua prática pedagógica ao abordar os conteúdos das disciplinas, tanto em Química como em Física. O valor de classificação fraco atribuído à sua prática pedagógica revela que ele, durante a abordagem de novos conteúdos, busca sempre estabelecer uma relação entre os conteúdos e conceitos já apresentados aos alunos. 
Quadro 2. Resumo dos Indicadores de análise das relações intradisciplinares dos professores P1 e P2 e seus resultados

\begin{tabular}{|c|c|c|c|}
\hline \multicolumn{4}{|c|}{ Relações Intradisciplinares } \\
\hline Professor & Indicador & Classificação & Descrição \\
\hline P1 & $\begin{array}{l}\text { Explicaşão/ } \\
\text { discussão dos } \\
\text { conteúdos ou } \\
\text { conceitos sob estudo. } \\
\\
\text { Nas atividades } \\
\text { realizadas em sala e } \\
\text { como tarefa de casa. }\end{array}$ & $\begin{array}{l}\text { Química: C++ } \\
\text { Física: C++ }\end{array}$ & $\begin{array}{l}\text { O professor nunca se refere aos conhecimentos } \\
\text { já estudados e às possíveis relações desses } \\
\text { com conteúdos e conceitos que estão em } \\
\text { estudo; O professor só recorre a assuntos já } \\
\text { trabalhados quando esses se mostram essenciais } \\
\text { para a compreensão dos novos conteúdos ou } \\
\text { conceitos. } \\
\text { Nas atividades que realiza com os alunos, o } \\
\text { professor não busca relacionar conteúdos } \\
\text { diferentes. Aborda apenas o que está sendo } \\
\text { trabalhado naquele momento. }\end{array}$ \\
\hline $\mathbf{P 2}$ & $\begin{array}{l}\text { Explicação/ } \\
\text { discussão dos } \\
\text { conteúdos ou } \\
\text { conceitos sob estudo. } \\
\text { Nas atividades } \\
\text { realizadas em sala e } \\
\text { como tarefa de casa. }\end{array}$ & $\begin{array}{l}\text { Química: C- } \\
\text { Física: C- } \\
\\
\text { Química: C++ } \\
\text { Física: C++ }\end{array}$ & $\begin{array}{l}\text { O professor sempre procura relacionar os novos } \\
\text { conteúdos/ou conceitos com os já trabalhados } \\
\text { anteriormente em sala de aula. } \\
\text { Nas atividades que realiza com os alunos, o } \\
\text { professor não busca relacionar conteúdos } \\
\text { diferentes. Aborda apenas o que está sendo } \\
\text { trabalhado naquele momento. }\end{array}$ \\
\hline
\end{tabular}

Fonte: elaborado pelos autores.

Na prática pedagógica dos professores P1 e P2 não são promovidas relações intradisciplinares nas atividades, tarefas e provas que os alunos realizam e, portanto, os conceitos transmitidos em ambas as disciplinas não são vistos como integrados, mas de forma isolada. $\mathrm{O}$ que nos chama a atenção no caso das questões apresentadas aos alunos para resolução é que, no caso do professor P1, essas não são extraídas do livro didático, mas no caso de P2 todas as questões são retiradas do livro. Acreditamos que o fato do professor P2 utilizar apenas o livro didático como origem das tarefas solicitadas não garante a ele que as relações intradisciplinares estejam presentes nessas questões. Desse modo, os professores precisam estar atentos aos materiais didáticos utilizados em suas aulas, buscando mediadores didáticos que, quando utilizadas como tarefas dos alunos, sejam capazes de promover as relações entre os diversos conteúdos da disciplina.

De acordo com Calado, Neves e Morais (2013), ao promover relações intradisciplinares no processo de ensino/aprendizagem, os professores podem levar à compreensão de conceitos de alta ordem, com maior poder de descrição, explicação, previsão e transferência. As relações intradisciplinares dizem respeito ao nível de integração dos diferentes assuntos abordados numa disciplina e refletem o nível de exigência conceitual requerido aos alunos. Portanto, a disciplina 
precisa de uma lógica de organização para que o professor possa gradativamente ir construindo com o alunado um conhecimento articulado, trazendo os temas anteriores para juntar aos novos aos quais estão relacionados (RODRIGUES, 2015).

Quadro 3. Resumo dos Indicadores de análise das relações interdisciplinares dos professores P1 e P2 e seus resultados

\begin{tabular}{|c|c|c|c|}
\hline \multicolumn{4}{|c|}{ Relações Interdisciplinares } \\
\hline Professor & Indicador & Classificação & Descrição \\
\hline \multirow[t]{2}{*}{ P1 } & $\begin{array}{l}\text { Nas atividades } \\
\text { realizadas em sala e } \\
\text { como tarefa de casa. }\end{array}$ & $\begin{array}{l}\text { Química: } \mathrm{C}^{++} \\
\text {Física: } \mathrm{C}^{++}\end{array}$ & $\begin{array}{l}\text { Nas atividades e tarefas que o professor } \\
\text { solicita aos alunos não são apresentadas } \\
\text { questões que relacionem o conteúdo e os } \\
\text { conceitos estudados com o conhecimento de } \\
\text { outras áreas. }\end{array}$ \\
\hline & $\begin{array}{l}\text { Explicação/ discussão } \\
\text { dos conteúdos ou conceitos } \\
\text { em estudo. }\end{array}$ & $\begin{array}{l}\text { Química: } C^{++} \\
\text {Física: } C^{++}\end{array}$ & $\begin{array}{l}\text { O professor nunca se refere ao conhecimento } \\
\text { de outras áreas e a possíveis relações desses } \\
\text { com conteúdos e conceitos que estão sendo } \\
\text { estudados. }\end{array}$ \\
\hline \multirow[t]{2}{*}{ P2 } & $\begin{array}{l}\text { Nas atividades } \\
\text { realizadas em sala e } \\
\text { como tarefa de casa. }\end{array}$ & $\begin{array}{l}\text { Química: } \mathrm{C}^{++} \\
\text {Física: } \mathrm{C}^{++}\end{array}$ & $\begin{array}{l}\text { Nas atividades e tarefas que o professor } \\
\text { solicita aos alunos não são apresentadas } \\
\text { questões que relacionem o conteúdo e os } \\
\text { conceitos estudados com o conhecimento de } \\
\text { outras áreas. }\end{array}$ \\
\hline & $\begin{array}{l}\text { Explicação/ discussão } \\
\text { dos conteúdos ou conceitos } \\
\text { em estudo. }\end{array}$ & $\begin{array}{l}\text { Química: } C^{++} \\
\text {Física: } C^{++}\end{array}$ & $\begin{array}{l}\text { O professor nunca se refere ao conhecimento } \\
\text { de outras áreas e a possíveis relações desses } \\
\text { com conteúdos e conceitos que estão sendo } \\
\text { estudados. }\end{array}$ \\
\hline
\end{tabular}

Fonte: elaborado pelos autores.

No caso das relações interdisciplinares (quadro 3), os valores de classificação muito forte apresentados nas duas disciplinas, tanto na prática pedagógica de P1 quanto na de P2, revelam que mesmo ao lecionar as duas disciplinas os professores não buscam promover uma relação entre elas, tampouco entre elas e outras disciplinas do currículo escolar. O fato de um mesmo professor lecionar Química e Física de forma tão isolada entre si é interpretado por nós como um efeito de sua formação inicial. Tanto o professor P1 quanto P2 revelaram nas entrevistas que tiveram uma formação muito mais próxima de um curso de bacharelado que de uma licenciatura.

Para Pierson e Neves (2001), o modelo de produção do conhecimento baseado na racionalidade técnica se caracteriza por uma fragmentação causada pela excessiva especialização da Ciência em suas disciplinas, sendo essa divisão um reflexo do paradigma positivista. $\mathrm{O}$ que podemos compreender é que a fragmentação do conhecimento vivida na formação inicial, com nítida separação entre as disciplinas específicas e pedagógicas no currículo do curso de Licen- 
ciatura em Química, produz efeitos para o ensino de Ciências, pois essa formação fragmentada se reflete na prática pedagógica desses professores e não contribui para que eles promovam relações interdisciplinares mesmo quando ensinam disciplinas científicas.

Além de afirmar que sua formação inicial estava mais próxima de um bacharelado que de uma licenciatura, o professor P1 não conta com o auxílio de uma coordenação pedagógica na escola em que ensina, o que também não favorece as discussões entre ele e seus colegas de trabalho acerca de suas práticas pedagógicas. Adicionalmente, P1 realizou um mestrado acadêmico em Química Analítica, e essas características ajudam a explicar a ausência da interdisciplinaridade em sua prática pedagógica.

Já o professor P2 conta com o auxílio de uma coordenação pedagógica na escola e com discussões entre ele e seus colegas de trabalho sobre suas práticas. Nesse caso, nos parece que as características da sua formação inicial dificultam estabelecer relações interdisciplinares em suas práticas pedagógicas nas disciplinas de Química e Física, tanto na abordagem dos conteúdos quanto na solicitação de tarefas, mesmo quando o professor conta com relações e discussões pedagógicas no trabalho.

Pensamos que, ao ensinar duas disciplinas tão próximas entre si, os professores poderiam buscar alternativas metodológicas para estabelecer relações interdisciplinares em suas práticas pedagógicas, pois assim poderiam contribuir para elevar o nível de exigência conceitual dos seus alunos, contribuindo para que eles tenham um melhor desempenho e compreensão dos conhecimentos científicos.

\section{Relação entre conhecimentos Acadêmicos e Não acadêmicos}

De acordo com Bernstein (1999), o conhecimento não acadêmico corresponde ao conhecimento do senso comum e consiste em um discurso oral, local, dependente e específico do contexto. Já o conhecimento acadêmico corresponde ao conhecimento escolar ou oficial, apresentando uma estrutura coerente e explícita e que se encontra hierarquicamente organizada.

Os resultados obtidos por meio dos indicadores de análise que tratam das relações entre os discursos acadêmicos e não acadêmicos dos professores P1 e P2 abordam dois momentos de aula: um, quando ocorre a discussão e explicação de conteúdos e conceitos em estudo, e outro, nas atividades e tarefas realizadas pelos alunos em sala de aula, conforme apresentado no quadro 4.

De acordo com Souza (2015), nas relações entre discursos, são os conhecimentos acadêmicos que geralmente assumem o maior estatuto no contexto escolar, mas essas relações podem ser mais equilibradas em uma prática pedagógica. Como demonstra o quadro 4 , na prática pedagógica do professor P1 os discursos acadêmicos prevalecem durante a explicação e a discussão de conceitos, tanto nas aulas de Química como nas de Física. No caso do professor P2, os discursos acadêmicos prevalecem mais durante a explicação e a discussão de conceitos nas aulas de Química. Já nas aulas de Física foi possível observar um número maior de momentos em que esse professor busca relacionar esses dois tipos de conhecimento, embora os acadêmicos sejam sempre favorecidos.

Pensamos que o valor de classificação forte para a disciplina de Física apresentado por P2 ocorre como uma tentativa do professor em facilitar aos alunos uma melhor compreensão dos conceitos sob estudo. Isso se evidencia quando nessa disciplina ele recorre mais a exem- 
plificações dos conteúdos abordados, e busca relacionar os conhecimentos acadêmicos com os conhecimentos não acadêmicos. Durante a entrevista realizada com o professor P2, ele nos conta que o fato de lecionar a disciplina de Física por quinze anos contribuiu para adquirir muito conhecimento, porém ele considera que esse ainda não é suficiente para lecionar a disciplina.

Quadro 4. Resumo dos Indicadores de análise das relações entre conhecimentos acadêmicos e não acadêmicos dos professores P1 e P2 e seus resultados

\begin{tabular}{|c|c|c|c|}
\hline \multicolumn{4}{|c|}{ Relações entre Conhecimentos Acadêmicos e Não Acadêmicos } \\
\hline Professor & Indicador & Classificação & Descrição \\
\hline \multirow[t]{2}{*}{ P1 } & $\begin{array}{l}\text { Explicação/discussão dos } \\
\text { conteúdos ou conceitos sob } \\
\text { estudo. }\end{array}$ & $\begin{array}{l}\text { Química: } \mathrm{C}^{++} \\
\text {Física: } \mathrm{C}^{++}\end{array}$ & $\begin{array}{l}\text { O professor dinamiza a exploração e a } \\
\text { discussão dos temas em estudo, abordando } \\
\text { exclusivamente conceitos do conhecimento } \\
\text { científico. }\end{array}$ \\
\hline & $\begin{array}{l}\text { Nas atividades a realizar } \\
\text { em sala e como tarefa de } \\
\text { casa. }\end{array}$ & $\begin{array}{l}\text { Química: } \mathrm{C}^{++} \\
\text {Física: } \mathrm{C}^{++}\end{array}$ & $\begin{array}{l}\text { As atividades e tarefas solicitadas pelo } \\
\text { professor abordam apenas conhecimentos } \\
\text { científicos. }\end{array}$ \\
\hline \multirow[t]{2}{*}{ P2 } & $\begin{array}{l}\text { Explicaşão/discussão dos } \\
\text { conteúdos ou conceitos em } \\
\text { estudo. }\end{array}$ & $\begin{array}{l}\text { Química: } \mathrm{C}^{++} \\
\text {Física: } \mathrm{C}^{+}\end{array}$ & $\begin{array}{l}\text { O professor dinamiza a exploração e a } \\
\text { discussão dos temas em estudo, abordando } \\
\text { exclusivamente o conhecimento científico. } \\
\text { Embora haja maior incidência dos } \\
\text { conhecimentos científicos, as relações entre } \\
\text { os conhecimentos científicos e os não } \\
\text { científicos também são contempladas. }\end{array}$ \\
\hline & $\begin{array}{l}\text { Nas atividades a realizar } \\
\text { em sala e como tarefa de } \\
\text { casa. }\end{array}$ & $\begin{array}{l}\text { Química: } C^{++} \\
\text {Física: } C^{++}\end{array}$ & $\begin{array}{l}\text { As atividades e tarefas solicitadas pelo } \\
\text { professor abordam apenas conhecimentos } \\
\text { científicos. }\end{array}$ \\
\hline
\end{tabular}

Fonte: elaborado pelos autores.

Para Galian (2011), a relevância do estabelecimento de relações entre o conhecimento acadêmico e o não acadêmico para a exigência conceitual reside no fato de que aquilo que os alunos sabem acerca dos fenômenos estudados pode ser tratado como ponto de partida e, a partir daí, se pode avançar para conhecimentos e competências mais complexos. A aquisição da linguagem científica pelos alunos é facilitada quando se permite que o conhecimento científico e teórico se desenvolva com a utilização de uma linguagem próxima àquela dos alunos, relacionando-se o conhecimento científico com problemas e fenômenos conhecidos pelos alunos, respeitando os conhecimentos que adquirem na comunidade em que vivem, para que interpretem e aprendam conceitos e fenômenos do conhecimento científico (SOUZA, 2015).

Quando analisamos as atividades e tarefas que os professores solicitam aos alunos, observamos as mesmas características em suas práticas, ou seja, a predominância dos conhecimentos acadêmicos sobre os não acadêmicos. Castro (2006) afirma que na educação científica, além dos conteúdos científicos, os conhecimentos não científicos devem ser enfatizados, pois 
também estabelecem relações com a natureza da Ciência. Dessa forma, aspectos como a metodologia da Ciência, a forma como a Ciência evolui, a relação entre Ciência, a sociedade e a tecnologia, as relações que se estabelecem dentro da comunidade científica, devem ser considerados importantes no âmbito da educação científica.

\section{Grau de complexidade dos conhecimentos científicos}

De acordo com Ferreira (2014), a complexidade do conhecimento científico está baseada na distinção entre fatos, fatos generalizados, conceitos simples, conceitos complexos, temas unificadores e teorias. Assim como no trabalho de Souza (2015), utilizaremos em nossa análise a forma como os conhecimentos científicos são cobrados nas atividades e avaliações que o professor desenvolve com seus alunos. Para analisar as atividades como provas, atividades avaliativas e exercícios, levamos em consideração as competências presentes nas questões.

$\mathrm{O}$ indicador de análise construído para caracterizar e analisar a complexidade dos conhecimentos científicos contém três descritores que correspondem a três graus de complexidade do conhecimento científico. O grau 1 de complexidade apresenta competências simples, como recordar e identificar fatos e conceitos de baixo nível de abstração do conhecimento científico. O grau 2 de complexidade apresenta competências mais complexas do que o grau 1, como comparar, classificar e relacionar conceitos de baixo nível de abstração do conhecimento científico. O grau 3 de complexidade apresenta competências mais elevadas, como analogias, síntese, dedução e argumentação de conceitos de elevado nível de abstração, como teorias e temas unificadores. Vejamos os resultados de nossas análises no quadro 5.

Tanto na disciplina de Química quanto na de Física as tarefas que o professor P1 solicita aos alunos apresentam questões de nível de complexidade simples e mais complexo (Graus 1 e 2), porém todas com baixo nível de abstração. Já com respeito ao professor P2, na disciplina de Química, foi observada uma maior incidência de questões de ordem mais complexa (Grau 2). Na disciplina de Física, as questões que apresentam graus de complexidade 1 e 2 são as mais solicitadas aos alunos, porém todas apresentam baixo nível de abstração do conhecimento.

Pensamos que a formação inicial desses professores não contribuiu para que eles adquirissem um conhecimento mais elaborado da didática e das metodologias de ensino das Ciências. Aulas práticas, questões contextualizadas, questões problematizadas e questões de temas gerais e unificadores, que estão ausentes nas práticas pedagógicas desses professores, se contempladas em suas metodologias de ensino, poderiam colaborar para ensinar Química e Física sem prejuízo do nível de complexidade dos conhecimentos exigidos para uma melhor aprendizagem dos alunos.

No que se refere à exigência conceitual nas disciplinas de Química e Física do professor P1, existe uma forte predominância dos conhecimentos científicos, sendo esses abordados de forma a não favorecer as relações entre os conhecimentos dessas disciplinas ou mesmo entre outras disciplinas. Os conhecimentos prévios dos alunos não são levados em consideração e as questões das atividades e as avaliações da aprendizagem apresentam baixa complexidade e baixa abstração do conhecimento científico. Com base em nossos resultados podemos notar que a prática pedagógica do professor P1 para as dimensões investigadas, envolvendo a exigência conceitual, apresenta muitas semelhanças quando ele ensina Química e Física. 
Quadro 5. Resumo dos Indicadores de análise da complexidade dos conhecimentos científicos dos professores P1 e P2 e seus resultados

\begin{tabular}{|c|c|c|c|}
\hline \multicolumn{4}{|c|}{ Complexidade dos Conhecimentos Científicos } \\
\hline Professor & Indicador & Grau & Descrição \\
\hline P1 & $\begin{array}{l}\text { Tarefas de } \\
\text { classel } \\
\text { extraclasse }\end{array}$ & $\begin{array}{l}\text { Química: } \\
\text { Grau 1/Grau } 2 \\
\text { Física: } \\
\text { Grau 1/Grau } 2\end{array}$ & $\begin{array}{l}\text { Grau } 1 \text { - Apresenta competências simples, como } \\
\text { recordar e identificar fatos e conceitos de baixo } \\
\text { nível de abstração do conhecimento científico. } \\
\text { Grau } 2 \text { - Competências mais complexas que o grau 1, } \\
\text { como comparar, classificar e relacionar conceitos de } \\
\text { baixo nível de abstração do conhecimento científico. }\end{array}$ \\
\hline P2 & $\begin{array}{l}\text { Tarefas de } \\
\text { classel } \\
\text { extraclasse }\end{array}$ & $\begin{array}{l}\text { Química: } \\
\text { Grau } 2 \\
\text { Física: } \\
\text { Grau 1/Grau } 2\end{array}$ & $\begin{array}{l}\text { Grau } 2 \text { - Competências mais complexas que o grau 1, } \\
\text { como comparar, classificar e relacionar conceitos de } \\
\text { baixo nível de abstração do conhecimento científico. } \\
\text { Grau } 1 \text { - Apresenta competências simples, como } \\
\text { recordar e identificar fatos e conceitos de baixo } \\
\text { nível de abstração do conhecimento científico. }\end{array}$ \\
\hline
\end{tabular}

Fonte: elaborado pelos autores.

\section{A prática pedagógica do professor P1}

Também verificamos, por meio de entrevista, que as relações entre esse professor e a direção escolar e entre a escola e os pais dos alunos influenciam a forma como P1 desenvolve a sua prática pedagógica, pois, por exemplo, ele argumenta não realizar aulas de laboratório devido à limitada infraestrutura que não comporta o número de alunos de suas turmas. Ele tampouco solicita atividades extraclasses aos alunos, pois alega que esses não contam com o auxílio da família para ajudá-los nas tarefas de casa, e também não utiliza o livro didático fornecido pela escola, pois de acordo com ele os livros adotados pela escola não foram aqueles indicados pelos professores que ministram essas disciplinas. $\mathrm{O}$ fato de o professor $\mathrm{P} 1$ não solicitar tarefas extraclasse significa que o segundo local de aquisição do conhecimento escolar - a família - não é levado em consideração em sua prática pedagógica, o que pode acarretar aos alunos dificuldades em compreender os conteúdos estudados e, consequentemente, um menor desempenho nas disciplinas.

\section{A prática pedagógica do professor P2}

Também não observamos diferenças significativas na prática pedagógica do professor P2 quanto ao nível de exigência conceitual quando ensina Química e Física e, de forma geral, o que se verifica é uma forte predominância dos conhecimentos científicos, sendo esses abordados de forma a não favorecer as relações entre os conhecimentos entre essas outras disciplinas. $\mathrm{O}$ 
conhecimento prévio dos alunos é levado em consideração em poucos momentos, bem como os conhecimentos de senso comum. As questões das atividades e avaliações da aprendizagem apresentam baixa complexidade em Física e complexidade mais elevada em Química, porém de baixa abstração do conhecimento científico nas duas disciplinas.

De acordo os nossos resultados, a prática pedagógica do professor P2 nas dimensões da exigência conceitual também apresenta mais semelhanças entre Química e Física do que diferenças. O professor P2 tem a seu favor a boa estrutura escolar, tanto física quanto de pessoal; a condição socioeconômica dos alunos, são provenientes de classe média baixa; o auxílio dos pais na instrução dos alunos; e o apoio pedagógico da escola que ele obtém para melhor desenvolver seu trabalho em sala de aula.

\section{Considerações finais}

Embora nosso estudo aponte que a exigência conceitual das tarefas e conteúdos não sofra muitas modificações quando esses professores formados em Química lecionam Física, foi possível observar que o contexto escolar no qual cada professor está inserido também contribui para as características de suas práticas pedagógicas e incidem nos níveis de exigência conceitual. Ao refletirmos sobre os resultados de nossa investigação reiteramos que o fato dos professores P1 e P2 reproduzirem características de suas práticas pedagógicas em Química quando lecionam Física demonstra uma tentativa deles em não produzir práticas distintas que possam prejudicar na aprendizagem dos alunos na disciplina de Física. No entanto, essa tentativa é um indicativo de que falta a esses professores o conhecimento de elementos didáticos para o ensino, que não foram devidamente contemplados na sua formação. Desse modo, a formação inicial desses professores promove influências em suas práticas pedagógicas de forma a não diferenciá-las quando lecionam uma disciplina diferente da sua formação.

Pensamos que as semelhanças encontradas nas práticas pedagógicas dos professores investigados não devam contribuir para uma visão de que os elevados índices de professores de Ciências que atuam na docência sem a formação específica na área não seja um grande problema da educação no país. Nossos resultados não asseguram uma generalização de como professores de Química desenvolvem seu trabalho docente quando também lecionam Física, mas trazem reflexões de como suas práticas podem ser desenvolvidas. Acreditamos que nossa pesquisa vem contribuir com os estudos desenvolvidos nessa temática, pois apontamos uma realidade no ensino de Ciências que pode estar ocorrendo em outros contextos escolares.

\section{Agradecimentos}

Os autores agradecem o financiamento do Conselho Nacional de Desenvolvimento Científico e Tecnológico (CNPq) e à Fundação de Amparo à Pesquisa do Estado da Bahia (Fabesp). 
A exigência conceitual na prática pedagógica ...

\section{Referências}

BERNSTEIN, B. Pedagogía, control simbólico e identidad: teoría, investigación y crítica. Madrid: Morata, 1998.

BERNSTEIN, B. Vertical and horizontal discourse: an essay. British Journal of Sociology of Education, Abingdon, v. 20, n. 2, p. 157-173, 1999. Disponível em: <https://doi. org/10.1080/01425699995380>. Acesso em: 9 out. 2018.

BRASIL. Tribunal de Contas da União. Relatório de auditoria: fiscalização no 177/2013. Relatório de auditoria coordenada no ensino médio. Brasillia, 2014. Disponível em: <https:// www.senado.gov.br/comissoes/CE/tcu/relatorio.pdf> Acesso em: 10 out. 2018.

CALADO, S.; NEVES, I. P.; MORAIS, A. M. Conceptual demand of science curricula: a study at the middle school level. Pedagogies: an international journal, Philadelphia, v. 8, n. 3, p. 255-277, 2013. Disponível em: <https://doi.org/10.1080/1554480X.2013.795698>. Acesso em: 16 nov. 2016.

CASTRO, S. T. A construção da ciência na educação científica do ensino secundário: análise do novo programa de biologia e geologia do $10^{\circ}$ ano. 2006. 303 f. Dissertação (Mestrado em Educação) - Faculdade de Ciências e Tecnologia, Universidade de Coimbra, Coimbra, 2006. Disponível em: < http://essa.ie.ulisboa.pt/publicacoes_teses_texto.htm>. Acesso em: 13 dez. 2016.

COIMBRA, J. A. A. Considerações sobre a interdisciplinaridade. In: PHILLIPI JUNIOR, A. et al. (Org.). Interdisciplinaridade em ciências ambientais. São Paulo: Signus, 2000. p. 52-70.

DOMINGOS, A. M. et al. A teoria de Bernstein em sociologia da educação. Lisboa: Fundação Colouste Gulbenkian, 1986.

FERREIRA, S. Trabalho prático em biologia e geologia no ensino secundário: estudo dos documentos oficiais e suas recontextualizações nas práticas dos professores. 2014. 583 f. Tese (Doutorado em Educação) - Instituto de Educação, Universidade de Lisboa, Lisboa, 2014. Disponível em: <http://hdl.handle.net/10451/15495>. Acesso em: 31 out. 16.

GALIAN, C. V. A recontextualização e o nível de exigência conceitual do conhecimento escolar. Educação \& Pesquisa, São Paulo, v. 37, n. 4, p. 763-777, 2011. Disponível em: <https://doi.org/10.1590/S1517-97022011000400006>. Acesso em: 16 nov. 2016.

INEP. Censo escolar 2013: perfil da docência no ensino médio regular. Brasília, 2015. Disponível em: <https://tinyurl.com/y73163b8>. Acesso em: 16 nov. 2016.

INEP. Censo escolar 2017: notas estatísticas. Brasília, 2018a. Disponível em: <http:// download.inep.gov.br/educacao_basica/censo_escolar/notas_estatisticas/2018/notas_ estatisticas_Censo_Escolar_2017.pdf>. Acesso em: 10 nov. 2018.

INEP. Relatório do segundo ciclo de monitoramento das metas do plano nacional de educação 2018. Brasilia, 2018b. Disponível em: <http:/ / portal.inep.gov.br/informacao-dapublicacao/-/asset_publisher/6JYIsGMAMkW1/document/id/1476034>. Acesso em: 10 nov. 2018. 
MORAIS, A. M. Influência do nível de exigência conceitual dos professores no sucesso dos alunos em ciências: um estudo sociológico. Revista de Educação, Lisboa, v. 2, n.1, p. 62-80, 1991.

MORAIS, A. M.; NEVES, I. P. Estruturas de conhecimento e exigência conceptual na educação em ciências. Educação, Sociedade \& Culturas, Porto, n. 37, p. 63-88, 2012. Disponível em: <https://www.fpce.up.pt/ciie/sites/default/files/ESC37_A_Morais_I_ Neves.pdf >. Acesso em: 10 out. 2018.

MORENO, A. C.; TENENTE, L.; LUIZ, G. Resultado do ENEM 2014 por escola é divulgado pelo INEP; veja a lista. G1, Rio de Janeiro, 5 ago. 2015. Disponível em: < http:/ / g1.globo.com/educacao/noticia/2015/08/resultado-do-enem-2014-por-escola-e-divulgadopelo-inep-veja-lista.html>. Acesso em: 10 out. 2018.

PIERSON, A. H. C; NEVES, M. R. Interdisciplinaridade na formação de professores de ciências: conhecendo obstáculos. Revista Brasileira de Pesquisa em Educação em Ciências, Belo Horizonte, v. 1, n. 2, p. 19-30, 2001. Disponível em: <http:/ /www. educadores.diaadia.pr.gov.br/arquivos/File/2010/artigos_teses/Biologia/Artigos/ interdisciplinas.pdf>. Acesso em: 08 dez. 2016.

RODRIGUES, A. C. C. Relações intradisciplinares e interdisciplinares no ensino da didática no curso de pedagogia. In: REUNIÃO NACIONAL DA ANPED, 37., 2015, Florianópolis. Anais eletrônicos... Florianópolis: ANPED, 2015. Disponível em: <http://www.anped.org. br/sites/default/files/trabalho-gt04-3686.pdf>. Acesso em: 08 dez. 2016.

\section{SOUZA, G. S. M. A influência do contexto social sobre a prática pedagógica de}

química: uma análise na perspectiva de Basil Bernstein. 2015. 160 f. Dissertação (Mestrado em Educação Científica e Formação de Professores) - Universidade Estadual do Sudoeste da Bahia, Jequié, 2015.

Artigo recebido em 13/03/2018. Aceito em 18/06/2018.

Contato: Universidade Estadual do Sudoeste da Bahia, Departamento de Ciências e Tecnologias, Rua José Moreira Sobrinho, S/N, Jequiezinho, Jequié, BA, 45200-000, Brasil. 